\title{
As limitacõoes do racionalismo emancipador eurocêntrico à luz do pluralismo jurídico enquanto criticidade periférica*
}

\author{
Antonio Carlos Wolkmer"* \\ Lucas Machado Fagundes"
}

Recebido: 14 de janeiro de 2015 • Aprovado: 19 de outubro de 2016

DOI: $10.22395 /$ ojum.vl6n3la4

\section{RESUMO}

O pluralismo jurídico apresenta a problematização da fonte do direito não ser somente o Estado, pois as comunidades organizadas também produzem normas. Logo, qual seria a fundamentação dessa compreensão jurídica plural? É possível encontrar uma racionalidade de tipo emancipatória que visualiza o pluralismo jurídico como capacidade racional de emancipar os sujeitos em dada situação de opressão. Contudo, a ideia desta racionalidade deve ser observada em uma realidade histórica concreta e isso demanda a observação do tipo de racionalidade enquanto potencialidade crítica do direito. Ora, o trabalho considera as limitações do racionalismo emancipador e explora o caráter de criticidade do pluralismo jurídico na realidade periférica. O objetivo geral do estudo é refletir sobre os limites do racionalismo emancipatório e, de forma específica renovar a perspectiva da racionalidade emancipatória no horizonte pluralista da libertação. Tais objetivos serão buscados por meio de uma pesquisa bibliográfica e de uma metodologia analética. Portanto, a contribuição do estudo é abrir o horizonte emancipador como fenômeno intramoderno e verificar a existência de outras facetas.

Palavras-chave: emancipação; juridicidade crítica; libertação; pluralismo jurídico; racionalidade.

Este artigo foi elaborado como fruto do trabalho de pesquisa desenvolvido no grupo de pesquisa "Pensamento Jurídico Crítico Latino-americano", vinculado ao Programa de Mestrado em Direitos Humanos e Sociedade da Universidade do Extremo Sul Catarinense (Unesc). O artigo foi revisado e ampliado, e sua bibliografia, atualizada da sua versão original.

* Professor titular aposentado no Programa de Pós-graduação em Direito da Universidade Federal de Santa Catarina (UFSC) e professor do Mestrado em Direito e Sociedade da Universidade La Salle (Unilasalle-RS) e Mestrado em Direitos Humanos da Unesc, Brasil. Doutor em Direito. É pesquisador nível 1-A do Conselho Nacional de Desenvolvimento Científico e Tecnológico (CNPq) e consultor Ad Hoc da Coordenação de Aperfeiçoamento de Pessoal de Nível Superior (Capes). Membro da Sociedad Argentina de Sociología Jurídica, do Grupo de Trabalho do Conselho Latino-americano de Ciências Sociais (Clacso) (Argentina-Equador): "Pensamiento Jurídico Crítico". Professor visitante de cursos de pós-graduação em várias universidades do Brasil e do exterior (Argentina, Chile, Colômbia, Costa Rica, Espanha, Itália, México, Peru e Venezuela). Autor de vários livros, dentre os quais: Pluralismo jurídico: fundamentos de una nueva cultura en el derecho. Sevilla: Mad, 2006 Crítica Jurídica en América Latina. México: Florianópolis: Nepe - Núcleo de Estudos e Prática Emancipatórias, 2013; Teoría crítica del derecho desde América Latina. Madrid: Akal, 2017. Correio eletrônico: wolkmer@yahoo.com.br

... Doutor e Mestre em Direito pela UFSC. Pesquisador do Núcleo de Pensamento Jurídico Crítico Latino-americano (coordenador da linha Constitucionalismo Crítico) da Unesc. Professor do Mestrado em Direitos Humanos e Sociedade da Unesc e professor convidado do Mestrado em Direitos Humanos da Universidad Autónoma de San Luis de Potosí (UASLP), México. Membro do Grupo de Trabalho do Clacso: "Crítica Jurídica Latinoamericana". Correio eletrônico: lucas-sul@hotmail.com 


\title{
The limitations of eurocentric emancipating rationalism to light of legal pluralism as peripheral criticality
}

\begin{abstract}
The juridical pluralism shows that the problem of the law sources not only from the State because organized communities also produce norms. Then, which would be the basis of such plural juridical comprehension? It is possible to find an emancipation-type rationality which views the juridical pluralism as a reasonable capacity to emancipate the individuals in a specific situation of oppression. However, the idea of such rationality should be observed within a concrete historical reality and that implies the observation of the type of rationality as critical potentiality of law. This article includes the limitations of emancipating rationalism and explores the criticality of juridical pluralism in the peripheral reality. The general objective of the study is to make a reflection on the limitations of emancipating rationalism and, specifically, to renew the perspective of emancipating rationality in the pluralist horizon of liberation. Such objectives will be reached through a bibliographic research and an analytical methodology. Hence, the contribution of this study is to open the emancipating horizon as an intra-modern phenomenon and to verify the existence of other aspects.
\end{abstract}

Key words: Rationality; emancipation; juridical pluralism; liberation; critical legality. 


\section{INTRODUCÃO}

A temática do pluralismo jurídico comporta um estudo que deve ser explorado levando em conta a realidade histórica na qual se desenvolveu bem como os elementos que fundamentam sua perspectiva em contexto determinado. Logo, justamente por essa preocupação em evidenciar os itens que dão características às diversas formas de manifestação da expressão jurídica nas realidades concretas, aparece a necessidade de investigar alguns desses elementos nos modelos desenvolvidos na modernidade periférica.

Assim, a proposta de pluralismo jurídico verificada nos países periféricos apresentam como pressuposto uma racionalidade de tipo emancipadora, que deve ser diferenciada daquela construída no Norte global, a qual gera a necessidade de repensar e renovar sua conceituação tendo em conta a perspectiva liberadora das sociedades em processo de descolonização. Preliminarmente, há que se ter presente a significação na tradição das ciências sociais ocidentais da conceituação radical de racionalidade emancipatória como expressão crítica ao modelo de racionalidade técnico-formal iluminista firmada na construção crítico-dialética, originada no bojo da vida concreta dos sujeitos excluídos - e em específico das necessidades históricas-, que envolve a totalidade em que estes se encontram, ou seja, nas relações sociais, políticas, jurídicas e econômicas do desenvolvimento do sistema-mundo capitalista.
Nessa direção, a tradição da modernidade ocidental edificou uma racionalidade como expressão de uma identidade cultural enquanto exigência e afirmação da "liberdade, emancipação e autodeterminação" (Wolkmer, 2012, p. 247). A problemática fundante de uma necessária racionalidade de cunho emancipatório se estabelece diante das mazelas de exclusão e das desigualdades que distorcem as relações políticas, sociais e econômicas.

Considerando tais questões, o presente estudo busca evidenciar os limites da racionalidade emancipatória de viés eurocêntrico ante o contexto de pluralismo jurídico em realidades periféricas, no qual a exigência por processos de libertação evidenciam uma necessidade concreta de repensar os fundamentos da pluralidade normativa em sua faceta comunitária participativa.

Tais objetivos serão buscados por meio de uma pesquisa bibliográfica e de uma metodologia analética, que irá privilegiar um diálogo interdisciplinar. Cabe explicitar que essa metodologia é a superação da negatividade dialética do sistema de direito e da ideia de injustiça produzida pelo sistema formal, é um aná (além) da dialética negativa que revela outras possibilidades mais ampliadas, ou seja, Outros Direitos (pluralismo jurídico).

Assim, as etapas do presente estudo compreendem primeiro o fundamento da racionalidade emancipatória no pluralismo jurídico, demonstrando como a perspectiva emancipatória fundamenta 
uma leitura crítica das relações entre Estado, sociedade e direitos, especialmente a partir do viés plural-jurídico-comunitário-participativo.

Na sequência, é explorado o pluralismo jurídico de tipo comunitário participativo como perspectiva de abertura ao horizonte de fundamentação latino-americano, ainda sem superar o campo emancipatório, mas abrindo possibilidades concretas para uma perspectiva de apontamento da ruptura e da subsunção da emancipação jurídica no viés do pensamento de libertação.

E, na última etapa, serão redefinidas as bases racionalistas do pluralismo jurídico no sentido da libertação, especificamente coletando as contribuições do pensamento filosófico da libertação dusseliano, em especial suas categorias e metodologia analética a fim de apontar os limites da racionalidade jurídica emancipatória quando contextualizada em uma realidade concreta que representa a exterioridade do projeto jurídico da modernidade.

Portanto, a contribuição do estudo é abrir o horizonte emancipador como fenômeno intramodernidade e verificar que a outra faceta é a libertação, que se propõe ir além dos limites da modernidade e da sua condição periférica; insurge, assim, uma racionalidade jurídica propositiva, protagonista e que emerge desde a condição encoberta do Outro, que não é somente, por vezes, marginal no sistema, mas também excluído da comunidade desse sistema.

\section{A RACIONALIDADE EMANCIPATÓRIA PRESENTE NO PLURALISMO JURÍDICO}

O pluralismo jurídico pode ser concebido de diferentes vieses: conservador, liberal, emancipador; porém, em todos eles, é sempre possível visualizar a ampliação da concepção unívoca da produção do direito. Assim, pretende contrapor ao monismo jurídico; nesse caso, o problema se encontra na pretensa razão científica de qualificar e definir o conceito de direito mais adequado para a leitura das práticas jurídicas, inclusive delimitando o campo de abrangência de qualquer outra prática que não seja a oficializada pelo Estado; a questão é refinada no movimento de coroar o sistema legiferante estatal como imperador do império jurídico.

Vale insistir na mesma perspectiva da questão do conceito de direito, quanto ao problema atemorizador não somente para os teóricos do pluralismo jurídico, como também para os seus críticos; via de regra, a ideia ou o conceito de direito trata de delimitar o campo de análise dos autores e, conforme é postulada esta ou aquela forma, pode-se concluir o seu posicionamento. Assim, a pretensão de denunciar toda a postura compreensível do direito emanado exclusivamente do Estado como conceito oficial, de imediato exclui os demais conceitos ampliados, como também o fazem, de maneira inversa, aqueles ampliados para outras manifestações ou aportes conceituais, mas que, ao final, reconhecem a oficialidade do direito estatal, eis o problema central. 
Parece que a definição do conceito de direito serve para sanar os deficit da ficção e do imaginário jurídico, pois, desde a racionalização iluminista e a posterior cientificização formalista da teoria da unicidade, o direito está imerso e contemplado na sua própria definição — confundida com a fonte-. Qualquer outra manifestação externa à soberba conceitual que envolve seu legalismo é rechaçada por não conter conteúdo "legítimo", compreendido como sinônimo jurídico.

Assim, fatores que influenciam no campo jurídico, tais como a moral, a economia, a política, a religiosidade, a cultura e até mesmo a arte são desconsiderados pela impureza, e cabe desqualificá-los como influentes diante do fenômeno jurídico, indignos de serem conceituados como direito.

Ao contrário dessas posturas, encontra-se o pensamento do equatoriano Bolívar Echeverría (2012), segundo o qual um dos "qualificativos" eficazes da modernidade foi justamente compartimentar áreas e restringir suas conceituações em desconexões com o mundo vivo do qual surgiram. Pensar de maneira diferente seria, portanto, refletir sobre a postura crítica do equatoriano e traduzi-la para o campo jurídico, em que o formalismo do imaginário tradicional é o guardião da pureza conceitual. Qualquer tipologia que intenta reemergir o direito nos fatores que lhe causam fissuras conceituais acaba por deturpar a estrutura que constitui sua teorização e é duramente afastada da esfera dos estudos jurídicos, sendo recomendada a readequação em outros campos.

No momento, resta a evidência desse problema conceitual mais amplo como uma das variadas questões polêmicas que devem ser abordadas na maneira preliminar, com fulcro a anunciar a dimensão problematizadora do tema.

Isso é importante pois a maioria das concepções pluralistas jurídicas observa o conceito estatal de direito, seja para rechaçar o direito posto (como incompleto), seja para denunciá-lo como unilateral; porém, mantendo o cânone do debate ao sistema legal do Estado, sem, contudo, criticá-lo a partir de uma totalidade.

Com esse alerta, pode-se adiantar que os objetivos críticos devem abalar as estruturas que compõem a filosofia política da juridicidade liberal estatal. Logo, deixa-se esclarecido que, neste texto, o direito e os fenômenos jurídicos estão imersos em uma complexidade sociopolítica altamente fundamentada por filosofias hegemônicas, que afastam qualquer concepção estranha à sua estrutura, desvirtuam seus reais embasamentos e direcionam os juristas a posturas profundamente com o discurso de despolitização, adotando a ambiguidade como cânone e princípio político, descaracterizando os demais fatores implícitos.

Ora, a postura crítica deve localizar essas questões e, ao contrário das teorias tradicionais, não isolar o problema jurídico dos demais campos, mas sim trabalhar as relações que estes guardam com a 
totalidade, compreendendo que o isolamento do campo jurídico e mesmo sua redução para análise "pura" deixa escapar a riqueza de uma série de elementos que compõem sua natureza; sem compreender os pilares que deram aparatos para a sua formação, não se poderá refletir e criticar as estruturas que concretaram sua existência histórica, bem como a afirmação como conceito privilegiado e imaculado na esfera do imaginário jurídico tradicional.

O que se impõe ao pluralismo jurídico, ao menos no contexto da América Latina, é o enfrentamento à ambivalência ou à ambiguidade, pois, nessas latitudes, ele se manifesta como um fenômeno com potencialidade de conviver com o sistema jurídico monista (como imperador do conceito de direito), aceitando o conceito liberal de direito e sendo tolerado pelas esferas da multiculturalidade, que pressupõem a diferença, reconhecendo-a apenas.

Constitui-se, então, no fato de que o conceito de pluralismo jurídico possui determinada ambiguidade e pode acobertar manifestações conservadoras, emancipadoras ou libertárias, além de servir, em algumas tipologias, aos interesses classistas dominantes e às suas individualidades segregadoras, ou seja, favorecer aquilo que critica —o império legislativo do Estado-. Em resumo, o pluralismo jurídico que se limita a denunciar que o catálogo jurídico do Estado é incompleto ou insuficiente, ao afirmar que, fora do sistema jurídico moderno, existem leis diferentes que devem ser incluídas, na realidade, está aceitando a estrutura geral e pontuando apenas um viés.

Dessa maneira, o objetivo da pesquisa é explorar a concepção jurídica plural que possibilita ou não uma ruptura com o modelo da matriz institucional e cultural do Estado e do Direito no continente, conduzindo ao processo de refundação política e jurídica do Estado moderno e à libertação comunitária, fundamentada em práticas jurídicas insurgentes e instituintes de outras formas de organização social ou comunitária.

Enfim, a ideia do pluralismo jurídico, para esse contexto de transição paradigmática, é a possibilidade de aprofundar a reflexão na forma de libertação com o intuito de se obter uma leitura crítica das realidades na região; libertar do contexto histórico de submissão, uma conceituação que emerge da práxis libertadora, impregnada de complexidade, de desejos, de anseios e de necessidades materiais, isto é, categorias populares iludidas em discursos jurídicos abstratos e redutores da pluridiversidade pela régua elitista dominante ou por conceitos plurais fundamentados a partir do sistema de direito oficial.

O que importa é repensar o aspecto jurídico no âmbito geopolítico da busca e da valorização da cosmovisão autóctone, originária, campesina, afro-latino-americana, ou mesmo da racionalidade produzida pela criatividade gestada em espaços comunitários classificados conforme a subalteridade das vítimas da modernidade. 
Diante disso, de forma análoga ao problema do conceito de direito no pluralismo jurídico, é o tema da emancipação, pois, em geral, é relacionada com a ideia de reconhecimento jurídico e por via de inserção no catálogo de direito. A ambiguidade do conceito de emancipação no contexto da América Latina se deve no âmbito do pluralismo jurídico pelo fato de que se emancipa o outro sujeito como diferente, desconsiderando a sua condição na realidade histórica concreta — distinto —; ou seja, emancipar é reconhecer o outro como membro diferente na comunidade de comunicação ideal' e esquecer a sua condição na comunidade de comunicação real. Ora, nada mais que os movimentos jurídicos chamados emancipatórios buscam a incluir o outro no mesmo sistema que gera dominação e colonialidade.

Nesse sentido, cabe verificar tendências teóricas como o Pluralismo Jurídico Comunitário-participativo (PJCP), que adota entre as suas categorias fundamentadoras o viés emancipador. O PJCP tem como elemento finalizador a proposta de uma racionalidade emancipatória que se traduz na crítica ao modelo de racionalidade técnico-formal e se afirma por meio de uma perspectiva crítico-dialética, originada na vida concreta dos sujeitos - e, em específico, das necessidades históricas-; além disso, envolve a totalidade sistêmica em que estes se encontram, ou seja, nas relações sociais, políticas, jurídicas e econômicas no desenvolvimento da estrutura da modernidade.

Sobre essas duas categorias, ver Dussel (2005).
Para a teoria do PJCP, "[...] trata-se da construção de uma racionalidade como expressão de uma identidade cultural enquanto exigência e afirmação da liberdade, emancipação e autodeterminação" (Wolkmer, 2012, p. 247). A problemática fundante de uma necessária racionalidade emancipatória se estabelece diante das mazelas sociais que distorcem as relações políticas e sociais.

Soma-se aos elementos anteriores o contexto do declínio das práticas tradicionais de representação política, da crise na eficácia das estruturas judiciais morosas e estatais em responder à pluralidade das demandas e dos conflitos, do crescente aumento de bolsões de miséria e das novas relações colonizadoras de países ricos com nações em desenvolvimento. Nesse contexto, abre-se a discussão para a consciente busca de alternativas capazes de desencadear diretrizes, práticas e regulações voltadas para o reconhecimento à diferença (singular e coletiva) de uma vida humana com maior identidade, autonomia e dignidade. E, ante essa leitura sociopolítica, o pluralismo jurídico munido de racionalidade emancipatória pode oferecer algumas alternativas. Logo, a situação expressa a:
[...] nova relação entre Estado e Sociedade, em processo de lutas e superações multiculturais no âmbito local, criando um novo espaço comunitário, de caráter neo-estatal, que funde o Estado e a Sociedade no público: um espa- ço de decisões não controladas nem determinadas pelo Estado, mas induzidas pela sociedade. 
Nessa perspectiva, o pluralismo comprometido com a alteridade e com a diversidade cultural projeta-se como instrumento contra-hegemônico, porquanto mobiliza concretamente a relação mais direta entre novos sujeitos sociais e poder institucional, favorecendo a radicalização de um processo comunitário participativo, definindo mecanismos plurais de exercício democrático e viabilizando cenários de reconhecimento e de afirmação de Direitos Humanos. (Wolkmer, 2010, p. 41)

Na visão do autor espanhol David Sánchez Rubio, a proposta do pluralismo jurídico comunitário participativo defende o paradigma emancipador porque pode ser um instrumento eficaz na leitura e na reflexão sobre as consequências do processo de globalização no campo jurídico e também no sentido de que o direito se oferece como instrumento para os sujeitos coletivos ou comunitários protegerem-se na sua vulnerabilidade. Logo, para esse autor — que compartilha da perspectiva emancipatória do pluralismo jurídico-, a proposta deve ser entendida da seguinte maneira:

[...] como estratégia progressista de integração, busca promover e estimular a participação múltipla dos segmentos populares e os novos sujeitos coletivos de base. Trata-se de uma proposta de um tipo de pluralismo participativo e integrador que reflete as estruturas sociais dependentes. Frente a um pluralismo construído desde acima por aqueles que con- trolam o poder político, cultural e econômico dentro dos processos hegemônicos de globalização, invoca Wolkmer um pluralismo jurídico desde baixo, dos próprios sujeitos coletivos e fundado no desafio para construir uma nova hegemonia que contemple o equilíbrio entre a vontade geral e os interesses individuais. (Sánchez-Rubio, 2010, p. 55)

Nesse viés, considerando o mundo cada vez mais diversificado em multiplicidades emergentes, o pluralismo seria uma opção para leitura jurídica da complexidade social bem como permitiria compreender as práticas e as experiências históricas de centros desiguais de poder (relações entre Norte global e Sul global) e sujeitos excluídos, agindo de maneira a obter o justo nas suas relações.

Diante disso, para o autor, "[él um erro [...] negar em sua totalidade tanto o Direito oficial e o papel garantista do Estado como reduzir qualquer manifestação do jurídico ao padrão estatista" (Sánchez-Rubio, 2010, p. 61); ele afirma que a natureza da crítica emancipatória do pluralismo jurídico não opera na negação e no rechaço total dos outros padrões de juridicidade, mesmo o monismo estatal.

Desse modo, é possível perceber a importância em explorar e renovar a conceituação da racionalidade emancipatória presente no PJCP para compreender qual o ímpeto que guarda na relação sociopolítica e filosófica para uma realidade situada, como o caso das sociedades periféricas, em especial a da América Latina. Afinal, 
o ímpeto emancipatório apontado acima revela uma preocupação pela inclusão e pela manutenção do sistema de direito monista, apenas elencando um caráter tolerante com a diversidade de outras práticas que são integradas e controladas pelo sistema jurídico oficial.

\section{O PLURALISMO JURÍDICO COMUNITÁRIO- PARTICIPATIVO COMO POSSIBILIDADE PARA OUTRA RACIONALIDADE}

Verificada a centralidade da temática da emancipação social para o pluralismo jurídico em geral e a possibilidade que este oferece na leitura social do campo jurídico, vale explorar mais detalhadamente a questão da racionalidade como necessidade de emancipação, proposta como um dos cinco condicionantes que compõe a teoria do PJCP. Essa teoria assume uma faceta de intentar superar o paradigma da hegemonia cultural da modernidade capitalista e o domínio que o campo econômico exerce no processo de racionalização da vida cotidiana das novas sociabilidades (Wolkmer, 1994).

Ora, a racionalidade perversa lógico-instrumental, que foi elaborada e sistematizada de maneira estrutural por Max Weber, recebe críticas dos autores oriundos da tradição marxista que conseguem vislumbrar um horizonte radical de libertação (Wolkmer, 1994), em que deveria prevalecer o racionalismo crítico sobre o racionalismo tecnológico.

Assim, uma das principais propostas teórico-críticas que se desenvolveu foi aquela calcada na argumentação comunicativa de Jürgen Habermas, que se emprega a partir da interação humana-participativa. A problemática central do processo de reflexão dessa corrente crítica se situa no âmbito do avanço da opressão e da exploração no sentido de ocultação dos reais efeitos da racionalização, transparecendo que a dominação possa ser exercida de maneira pouco perceptível ou como efeito natural do processo; isso se opera na fusão entre opressão e racionalismo, e na técnica com a dominação (Wolkmer, 1994).

Essas manifestações hegemônicas e reprodutoras da dominação e da alienação, fetichizadas no sistema racional técnico-formal e instrumental para o benefício do sistema econômico-político imperante, e para a produção do poder concentrado nas elites dominantes que disputam entre si a hegemonia, levaram a que Habermas pudesse avançar sua crítica no sentido de elaborar alternativas.

[...] Habermas se propõe solucionar as "patologias sociais" atuais (medo, dominação, alienação etc.) através de uma vigorosa "ação comunicativa", embasada no entendimento concreto (empírico, fático), no consenso não-coagido e na convicção recíproca. Isso implica a mudança no paradigma da ação, a reordenação dos sujeitos sociais (de um sujeito que se articula em torno de objetos para sujeitos que se relacionam na perspectiva da intersubjetividade e da participação) e o abandono da "razão instrumental" insuficiente por uma razão "prático-discursiva", descentralizada, reconstruída e ampliada. 
[...] A racionalidade para Habermas não é mais uma faculdade abstrata, inerente ao indivíduo isolado, mas um procedimento argumentativo pelo qual dois ou mais sujeito se põem de acordo sobre questões relacionadas com a verdade, a justiça e a autenticidade. Desta maneira, a "razão comunicativa", enquanto razão prático-dialógica, redunda naquilo que em contexto social vivido e compartilhado por atores linguisticamente competentes, pode ser elaborado como querido e aceito por todos. (Wolkmer, 1994, p. 250)

No entanto, essa tipologia sofre de problemas visíveis (Wolkmer, 1994) quando analisada na especifidade do mundo periférico latino-americano; este se desdobra nos seguintes efeitos: inicialmente relacionado com a elaboração da racionalidade comunicativa, estabelecida por um contexto material concreto de manipulação da riqueza em elevado grau de desenvolvimento, fator que, no âmbito paupérrimo do continente, se torna difícil de verificar. Também há de se terem presentes as condições de liberdade, de autonomia e de igualdade material dos sujeitos envolvidos, como pressupostos para o exercício do agir comunicativo, elemento esse que, em contextos mais homogêneos, como no caso europeu, parece lógico, mas, aplicado em realidades complexas e fragmentadas, habitadas por profundas diversidades culturais, já se torna deveras hipotético; e último efeito a "[...] restrição é que este novo paradigma de ação dialógico-discursiva requer uma 'comunidade linguística ideal', de integralidade quase utópica, desprovida de engano, coação e irresponsabilidade" (Wolkmer, 1994, p. 252).

Nesse sentido, os processos de racionalização devem emanar das necessidades que fundam o agir para reprodução da vida humana; eis que a proposta de uma racionalidade emancipatória em sua condição crítica de que: "[...] dentre todos os mecanismos instrumentais, há de se optar por aquele mais capaz de romper com os obstáculos do velho paradigma e lançar as bases para um novo homem, uma nova sociedade, um novo comportamento e um novo conhecimento" (Wolkmer, 1994, p. 253).

Assim, muito se discute a respeito da superação da racionalidade instrumental moderna, dos limites, das linhas críticas e das principais perspectivas de superação, propondo uma racionalidade emancipadora, enquanto superação das incongruências produzidas pela própria modernidade eurocêntrica. Tal finalidade será utilizada por um pluralismo jurídico transformador no sentido de criticar o monismo estatal, fruto do sistema jurídico moderno.

Certamente, a fundamentação originária da racionalidade moderna da matriz iluminista revolucionária e sua prolongação na história moderna como maneira de cerceamento ideológico e produtor de alienação ${ }^{2}$ podem ser desdobradas como um processo cultural.

\footnotetext{
"La alienación de un pueblo o individuo singular es hacerle perder su ser al incorporarlo como momento, aspecto o instrumento del ser de otro. Aufhebung es subsunción (es incorporación
} 
A essência cultural da modernidade estabelecida, geradora do progresso material mas também responsável pelo cerceamento desintegrador da "condição humana", encontra seu desfecho numa racionalização de matriz iluminista, portadora de uma temporalidade inacabada que contribui para a alienação, massificação, coisificação e crises de subjetividade. (Wolkmer, 2001, p. 171)

Além da fundamentação cultural da racionalidade trabalhada, o autor acima dá enfoque na sua relação com o processo de mudança produzido e afirmado pós-revolução burguesa; no continente europeu, deixa evidente a conexão: "[...] o racionalismo ocidental surgiu nos marcos das sociedades modernas enquanto produto da especificidade econômica do mercantilismo e dos valores individualista-antropocêntricos emergentes" (Wolkmer, 2001, p. 171). Deve ser recordado que as duas principais matrizes que constituem a racionalidade moderna encontram-se na: "[...] a) a interpretação clássica de Max Weber sobre a racionalidade moderna; b)

en el todo por transformación o negación de lo asumido; negación del otro independiente y transformación como parte del todo). 2.5.5.2 La periferia geopolítica mundial, la mujer y el hijo son propiedad del centro, del varón y el adulto. Se aliena el ser del otro al descolocarlo de su propio centro; al hacerlo girar en torno del centro de la totalidad ajena. 2.5.5.3 La alienación, sin embargo, se juega esencialmente en la poíesis de una formación social". E. Dussel menciona que o direito totalizado produz a alienação do sujeito em uma ordem que se denominada "a legalidade da injustiça"; essa ideia de alienação se resume na perspectiva de totalizar a exterioridade, negando o outro na sua dimensão distinta e alheia ao contexto geopolítico dessa totalidade (Dussel, 2011, p. 96). a interpretação crítica da racionalidade iluminista através da tradição marxista (Lukács, Adorno e Horkheimer, Marcuse e Habermas)" (Wolkmer, 2001, p. 171). Nessa primeira linha, a racionalidade intelectiva é clarificada como "[...] o domínio da razão técnica disciplinada e do progresso instrumental que se impôs ao mundo imprevisível, mítico e mágico das sociedades primitivas" (Wolkmer, 2001, p. 171).

Trata-se da substituição da racionalidade ideológica mitificada nas superstições idealizadas pela fundamentação clerical/ religiosa ou então lidas pelas mitologias dos povos, compreendidas como aspectos culturais que compõem a história e a formação deles. De outro lado, a segunda interpretação faz uma verificação materialista não somente do fundamento ideológico ou filosófico, mas também inclui os resultados objetivos com intuito de formar ideias justificadoras do sistema ao momento emergente. Nessa perspectiva, a proposta de matriz weberiana não é compartida pela "[...] crítica marxista que identifica, no moderno processo de racionalização do mundo da vida, os sintomas negativos da alienação, dominação e retificação (coisificação)" (Wolkmer, 2001, p. 171). O desencobrimento do verdadeiro objetivo do paradigma racional eurocêntrico moderno pelas palavras de um de seus expoentes apresenta a seguinte constatação:

[...] Assim, a fetichização da vida, na sociedade capitalista, permite considerar a racionalização e a reificação como processo único. Na esteira aberta por Georg Lukács, Theodor Adorno e Max Hork- 
heimer, radicalizando a crítica à "racionalização como coisificação", são unânimes em reconhecer que a sociedade burguesa e sua cultura iluminista, com sua técnica e ciência, produziram um "desencantamento do mundo" que, em vez de conduzirem a liberdade e autonomia dos homens, favoreceram o domínio de uma "razão instrumental" opressora, totalitária e subjugadora da "razão emancipatória". (Wolkmer, 2001, p. 171)

Na obra em referência, é importante notar a relação do embasamento que produz a racionalidade moderna imbuída de outra ideia, o chamado mito do desenvolvimento, manifestado nos arquétipos que a engenharia racional da modernidade burguesa produziu sob a denominação de "tecnologia", no sentido de manter e aprofundar as estratégias capitalistas de dominação para o aumento da produção e do respectivo lucro à custa da exploração e da extração de energias humanas. Isto é, no caráter totalitário:

[...] dos princípios que fundamentam o Capitalismo avançado compreende uma "racionalidade tecnológica" que se personifica num aparato produtivo usado irracionalmente para criar automatização, conformismo e alienação. Neste universo de racionalização expressa pela civilização capitalista, que nega e oprime a "essência humana", a liberação revolucionária total deve resultar na conjunção de forças operacionalizadoras comprometidas com o predomínio do "racionalismo crítico" sobre o "racionalismo tecnológico" (tradicional, idealista). (Marcuse citado por Wolkmer, 2001, p. 173)

Uma vez exposta essa segunda interpretação, propõe outra corrente crítica com uma leitura mais aguda do fenômeno, em que não se apresenta meramente como crítica desconstrutiva ou desligitimadora, já que, até então, representaria o viés aproximado do pós-modernismo; ao contrário, aparece uma crítica com proposta de reconstrução, que reordena os esforços para uma filosofia da consciência; portanto,

$$
\begin{aligned}
& \text { [...] aparece a Escola de Frankfurt } \\
& \text { (principalmente Jürgen Habermas } \\
& \text { e Karl-Otto Apel) que não nega } \\
& \text { a razão, porém propõe corrigir } \\
& \text { e reconstruir a racionalidade } \\
& \text { moderna. Trata-se de uma racio- } \\
& \text { nalidade redirecionada para uma } \\
& \text { "razão comunicativa", embasada } \\
& \text { não mais numa filosofia da con- } \\
& \text { sciência e numa mera ontologia } \\
& \text { do conhecimento, mas firmada } \\
& \text { na interação humana participa- } \\
& \text { tiva, no livre consenso e na ação } \\
& \text { da argumentação comunicativa. } \\
& \text { (Wolkmer, 2001, p. 173) }
\end{aligned}
$$

Na denúncia a essa forma de fetichização ${ }^{3}$ do sistema racional moderno, há

3 "Llamamos fetichización al proceso por el que una totalidad se absolutiza, se cierra, se diviniza. La totalidad política se fetichiza cuando se adora a sí misma en el imperio (3.1.5) o en el totalitarismo nacionalista (3.1.6). La totalidad erótica se fetichiza cuando es constituida por la fascinación del falo perverso de la ideología machista (3.2.5-2.6). La totalidad cultural se fetichiza cuando la ideología imperial o ilustrada elitista aliena la cultura popular (3.3.6) o castra al hijo (3.3.5). El fetichismo es la muerte de la totalidad, del sistema, del discurso". (Dussel, 2011, p. 155). Desse ensinamento da 
de se destacarem as diferenças quanto à especificação dos interesses entre uma racionalidade crítica emancipadora e a racionalidade técnica ou instrumental:

\section{[...] deslocando a fundamentação da racionalidade para um foco de cunho "lingüístico-pragmático" ou "discursivo comunicativo". Agora, fica muito clara a emergên- cia de uma "racionalidade comu- nicativa" (é a razão prática ou dialógica consensual, constituída por enunciados prescritivos) que se opõe a uma "racionalidade cognitivo-instrumental" (razão lógico-formal ou técnico-instru- mental, constituída por enuncia- dos descritivos). (Wolkmer, 2001, p. 171)}

Assim, uma das especificidades em Habermas é justamente o deslocamento da singularidade do sujeito na racionalidade moderna para o conceito de comunidade de atores ou coletividade comunicativa; isso quer dizer que, se a ideia da modernidade assentou suas bases na abstração do sujeito individualizado e isolado, seguirá contrariamente a proposta comunicativa do autor da Escola de Frankfurt, na qual o sujeito se encontraria em conexão relacional com outro(s) sujeito(s) em um processo argumentativo de

filosofia da libertação de Dussel, deduzimos que o fetichismo jurídico é produzido quando a concepção de direito é reduzida ao monismo legal do pensamento e da cultura jurídica moderna; ao encerrar a compreensão jurídica dentro dessa lógica, olvida-se o pluralismo de produção normativa social e jurídica, diminui-se o impacto de uma interpretação jurídica mais ampliada e despolitiza-se o direito em sua capacidade de libertação. diálogo; logo, "[...] a razão comunicativa, enquanto razão prático-dialógica, redunda naquilo que em contexto social, vivido e compartilhado por atores linguisticamente competentes, pode ser elaborado como querido e aceito por todos" (Wolkmer, 2001, p. 171).

Por outro lado, cabe apontar os limites que imperiosamente há de se reconhecer na teoria de Habermas acerca de uma racionalidade comunicativa e essencialista; estes são refletidos desde o horizonte geopolítico e da historicidade dominada de espaços geográficos como no caso a América Latina. Na conta desses fenômenos, há que se aproximar da necessidade de pensar elementos críticos pela própria realidade periférica e, a partir de então, propor alternativas. Ora, é perceptível, nesse tipo de proposta, que não é o objetivo a total negação da importância dos elementos elencados, mas, seguindo a reflexão de Enrique Dussel (2005), subsumir criticamente esses elementos e trabalhar pelos próprios ares tropicais as contingências que forem se impondo aos processos sociais, políticos e jurídicos específicos; enfim, situando uma realidade histórica concreta.

Esse tipo de postura abre a possibilidade de pensar o pluralismo jurídico de forma diferente em relação às propostas teóricas até então desenvolvidas; esse encaminhamento torna-se a entrada para aprofundar os estudos em outros rumos e em outras direções. O movimento é de subsumir criticamente a perspectiva emancipatória como elemento desestabilizador do status quo jurídico moderno 
e, aproveitando a abertura teórica de integração e mobilização, potencializar um sentido histórico concreto da realidade periférica.

\section{REDEFININDO AS BASES RACIONALISTAS DO PLURALISMO JURIDICO NO SENTIDO DA LIBERTACÃO}

Privilegiando a proposta por uma racionalidade crítica, devem-se considerar algumas precauções quando refletir essa temática na realidade periférica, pois o que importa são as especificidades que impõem à verificação de alguns atos de renúncia e outros de aprofundamento nas questões materiais que compõem a complexidade da sociedade específica: "[d]este modo, o novo conceito de razão implica o abandono de todo e qualquer tipo de racionalização metafísica e (tecno)formalista equidistante da experiência concreta e da crescente pluralidade das formas de vida cotidiana" (Wolkmer, 2001, p. 176).

Aparece aqui a evidência necessária para perceber que o fenômeno da racionalização moderna reflete no campo jurídico uma observância das manifestações plurais em torno da produção e da reprodução da vida cotidiana como forma de organização social que, atravessada por questões culturais, conforma por si a essência que pode originar Outro Direito, principalmente, quando a negação das condições para essa produção e reprodução da vida, se apresenta com o impedimento do exercício legítimo de um princípio humano (viver e ter condições de vida), dando origem a uma tipologia jurídica insurgente que, pela sua própria natureza, só pode ser ilegal e contra a racionalidade e a filosofia moderna do direito formal no sistema-mundo - fundado com intuito de expansão capitalista e privilegiando determinados setores sociais-.

Naturalmente, a assertiva se insurge como projeção inovadora, que se efetiva no campo da educação (conscientização e cultura), em que opera por uma via de aprendizagem comprometida com a realidade fática, não abstrata, dos sujeitos subalternos envoltos no contexto de manutenção da marginalidade no sistema capitalista; essa alternativa é pensada privilegiando uma estratégia de educação libertadora, para a qual se afirma: "[...] comprometida com o processo de desmitificação e conscientização (um novo 'desencanto do mundo'), apta a levar e a permitir, por meio da dinâmica interativa 'consciência, ação, reflexão-transformação'" (Wolkmer, 2001, p. 176). Convoca para que não meramente as individualidades assumam esse processo, mas que também as identidades culturais, coletividades e experiências comunitárias tomem a responsabilidade pelo outro - a vítima do sistema injusto- e produzam experiências alternativas que provoquem a ampliação das possibilidades de desenvolver a vida com dignidade e extrapolem o horizonte reduzido pela racionalidade moderna (Wolkmer, 2001, p. 176).

Diante disso, ainda resta expor certas limitações conceituais na significação da proposta de racionalidade emancipatória, avançando na direção mais radical, 
legitimando-se enquanto racionalidade de configuração libertária. Ainda não se veem também as bases e os fundamentos das referências mencionadas em direção à potencialização autônoma e autodeterminada dos sujeitos ausentes da história oficial, pois as racionalidades da modernidade são expostas de maneira retórica por algumas escolas ou teorias críticas, o que equivale à crítica da própria modernidade. No entanto, mesmo que localize a origem da referida racionalidade pela filosofia fundamentadora da crítica, não busca afirmar uma metodologia ou perspectiva de pensamento para superá-la. Esses dois limites evidenciam que a teoria da racionalidade emancipatória (partindo da crítica europeia), apesar de indicar que as problemáticas refletidas pelas racionalidades críticas pensadas pelo centro do poder devem ser aplicadas na realidade regional periférica com algumas ponderações, não é considerada de forma enfática uma proposta de pensar as contingências continentais e subsumir criticamente a pós-modernidade como último momento de afirmação da modernidade em crise.

Acredita-se que uma proposta emancipadora ante as novas condições estruturais, há que incluir os sujeitos que estão postos na margem do processo social e político concretizado por meio da mundialidade capitalista sob a idealização da igualdade abstrata, sem considerar as condições materiais que diferenciam. Logo, a própria lógica inclusiva emancipadora não verifica os longínquos sujeitos exteriores ao sistema de forma independente como outros além do binômio da diferença-igualdade, seguindo aquilo que a pós-modernidade não consegue verificar —os sujeitos distintos-.

Esses sujeitos distintos, que são preconcebidos como sem capacidades racionais modernas, pois seus embasamentos ou fundamentos epistemológicos estão além das elementares "qualificadoras" do centro hegemônico e, muitas vezes, o desenvolvimento histórico cultural concreto é a própria experiência viva dos seus antepassados, ou seja, são estranhos a qualquer tipo de racionalidade produzida pela modernidade; ainda, além de dizimados e excluídos da comunidade científica e racional de comunicação, esses sujeitos distintos sofrem o processo de encobrimento das fontes de produção própria da sua epistemologia e, nesse processo, opera uma racionalidade colonizadora.

Ora, ainda que esses sujeitos sofram os desígnios da modernidade ou, na melhor das hipóteses, auferidas por meio de uma alteridade burguesa, eles tenham sido inclusos como um "si mesmo", tendo seu lugar cativo na margem do sistema social, conformando a abertura para disputa intrassistema, assim o chamado espaço de emancipação.

Dessa maneira, para esses sujeitos distintos, quando da emergência das racionalidades próprias, estas acabam sendo traduzidas no mundo moderno como mistificadoras, irrealistas ou mitológicas, mesmo que compartam de "cosmovisões históricas e raízes ancestrais". No caso da análise realizada pela sociologia tradicional, essas perspectivas acabam sendo repassadas para o grupo de categorias 
antropológicas, que pretendem considerar como fundamentais os aspectos desconsiderados pela racionalidade moderna; contudo, ao final, as cosmovisões são rechaçadas pelo modelo racional hegemônico e, muitas vezes, acabam abandonadas ou ocultadas.

Diante disso, para auxiliar na reflexão sociológica do tema, Enrique Dussel (2011) recorda a perspectiva semita, a qual se torna uma significativa interpretação crítica no ato de aproximação com a moderna racionalidade emancipadora:

La experiencia griega o indoeuropea (1.1.6) y la moderna europea (1.1.7) privilegiaron la relación hombre-naturaleza (como fysis o natura) porque comprendieron el ser como luz o como cogito, en ambos casos el ámbito del mundo y lo político queda definido como lo visto, dominado, controlado. Si por el contrario privilegiamos la espacialidad (proximidad o lejanía, centro o periferia) y lo político (dominador-dominado) (3.1), la posición hombre-hombre, que fue la experiencia originaria del semita (1.1.7) de la realidad como libertad, podremos iniciar un discurso filosófico desde otro origen. (p. 44)

E complementa:

No hablamos aquí del ir hacia una mesa, una silla, una cosa. Aproximarse a algo, llegar junto a ella para tomarla, comprarla, venderla, usarla. Aproximarse a las cosas lo denominaremos la proxemia. Hablamos aquí de aproximarnos en la fraternidad, acortar distancia hacia alguien que puede esperarnos o rechazarnos, darnos la mano o herirnos, besarnos o asesinarnos. (Dussel, 2011, p. 45)

Esse tipo de proximidade revela a alteridade libertadora e põe ênfase em determinados limites de racionalidades que se advogam "emancipadoras". O que se apresenta para reflexão são propostas racionalistas da modernidade, sejam novas, sejam as reformuladas criticamente, continuam gestadas ou pautadas pelos espaços que geram a crise do sistema. Para Enrique Dussel (2011), "[...] la 'falacia desarrollista' — de un Habermas, por ejemplo - pretende aplicar a 'todo planeta' (centro dominador y periferia dominada) el modelo del 'capitalismo tardío' - una 'falacia' de otro nivel" (p. 86).

Entretanto, para evitar equívocos, não se deve olvidar que as racionalidades "emancipadoras" possuem imenso e relevante potencial crítico, ao expor seus limites e principalmente ao subsumi-los em sua capacidade de luta, pois, para os marginais do sistema mundo, também é importante ocupar espaços como capacidade de mobilização política estratégica na superação dos obstáculos impostos pelas mazelas capitalistas.

No entanto, o que parece mais importante sob essa subsunção emancipadora é compreender que, além dos marginais, existem sujeitos na exterioridade da totalidade que não podem ser considerados em um diálogo ou ação comunicativa sem que se compreendam o distanciamento e a distinção histórica e social efetiva. Em 
razão disso, aquela proposta dialógica Norte-Sul (Santos, 2010) ou ação comunicativa se faz por dentro do sistema mundo entre iguais e diferentes da emancipação ante as injustiças do sistema, mas que, ao final, não buscam superá-lo.

Quando se qualificam no binômio iguais-diferentes, fala-se do mesmo sujeito histórico que ocupa o similar espaço em posições díspares em dado diálogo (de um lado, o dominador e, de outro, os dominados ou subsumidos como mão de obra explorada, ou utilizados como capacidade em potencial ao trabalho, mas que, na especulação econômica, são assediados como exército de reserva).

Então, ao refletir sobre a superação do referido modelo de pensamento em uma perspectiva libertadora, deve-se ter em conta que distinção não pode ser lida pela igualdade formal ou material, pois, além das consequências econômicas que embasam as críticas da segunda vertente exposta acima, também existem questões culturais e de desenvolvimento social que não podem ser lidas pela esfera marginal como resultado da economia do sistema, e aqui aparece o problema de outra maneira. Embora a exterioridade tenha sido produzida por esse ponto, as abordagens pela exterioridade são elaboradas na própria condição de Não-Ser, ausente, ignorado e, por vezes, incluso no sistema de maneira violenta. De tal modo, respondendo à pregunta "libertação do quê?", Dussel (2007) exibe um resumo esclarecedor:

A superação da razão cínico-ge-

\begin{abstract}
rencial (Administrativa mundial) do capitalismo (como sistema econômico), do liberalismo (como sistema político), do eurocentrismo (como idelologia), do machismo (na erótica), do predomínio da raça branca (como racismo), da destruição da natureza (na ecologia), etc., supõe a libertação de diversos tipos de vítimas oprimidas e/ou excluídas. É neste sentido que a ética da libertação se define como transmoderna (já que os pós-modernos são ainda eurocêntricos). (p. 65)
\end{abstract}

Diante da afirmação, a "outridade" desses sujeitos compõe a novidade que coloca em crise as propostas dos diálogos emancipadores, pois estes últimos têm sido pensados para a funcionalidade produtiva ou reprodutiva da reinvenção dos paradigmas modernos, ao passo que a alteridade presente na ética libertadora, por sua própria condição excluída do diálogo na sua matriz histórica ausente, é dotada de capacidades epistemológicas que não estão sob as ideias coletivistas (que partem de singularidades unidas com um propósito), mas sob cosmovisões que a própria etimologia da palavra revela, que não se explica no humanismo da juridicidade moderna com seus caracteres abstratos, eruditos e racionalistas positivados.

Finalmente, o que parece realmente importar para as realidades periféricas descoloniais é uma ética que promova a fundamentação libertadora ${ }^{4}$ com a afir-

\footnotetext{
"Trata-se de uma ética da vida, isto é, a vida humana é o conteúdo da ética. Por isso, desejamos aqui, desde o início, advertir o leitor sobre o
} 
mação da vida humana e da qualidade de desenvolvimento das suas distinções ou diferenças culturais, sob condições materiais de vida adequadas aos seus contextos sócio-históricos e que considere as capacidades dos sujeitos ausentes como modo de produção epistemológico e de desenvolvimento não subsumido na produção cientificista moderna ${ }^{5}$, mas sim autônomo e autodeterminado.

\subsection{A questão da emancipação racionalista moderna no horizonte do pluralismo juridico latino-ameri- cano}

Tendo em vista a premissa apontada acima, vale recordar que o pressuposto de uma racionalidade (que não deixa de ser crítica) visualizada em um PJCP, ante as novas condições presentes, minimiza os demais pressupostos condicionantes dessa pluralidade transformadora.

Destarte, implica obrigatoriamente direcionar tal proposta emancipadora a um pensamento de liberação presente na

sentido de uma ética de conteúdo ou material. O projeto de uma ética da libertação entra em jogo de maneira própria a partir do exercício da crítica ética [...], onde se afirma a dignidade negada da vida da vítima, do oprimido ou excluído [...]. É em função das vítimas, dos dominados ou excluídos que se necessita esclarecer o aspecto material da ética para bem fundá-la e poder, a partir dela, dar o passo crítico". (Dussel, 2007, p. 93).

5 "A ética da libertação justifica que possam enunciar "juízos de fato" com relação à vida ou à morte do sujeito ético. Não nos referimos a juízos de fato da razão instrumental que procedem do cálculo meio-fim, formais, mas sim juízos referentes à produção, à reprodução ou ao desenvolvimento da vida humana, materiais (mas não materialidade no sentido weberiano) e a partir de cujo âmbito podem ser julgados criticamente os fins e valores". (Dussel, 2007, p. 136).
América Latina. Afinal, nem todo pluralismo jurídico na tradição latino-americana foi liberador, pois está impregnado por uma tradição colonizadora. Tal foi o caso das leis de Índias, ao se produzir um pluralismo jurídico que mantinha "emancipadas" as práticas jurídicas indígenas sob as condicionantes impostas pela Igreja Católica e pelos ditames da Coroa Ibérica; ou seja, as leis e as constituições emancipadoras das nascentes nações latino-americanas conduziram apenas à mudança de metrópole, assim como as leis sociais da revolução social mexicana (como exemplo) preparam os trabalhadores e a mão de obra indígena e campesina (espoliada das suas terras pelas leis de amortização alguns anos antes da revolução jurídica-social de 1917) para um sistema de exploração capitalista incipiente, e assim por diante ${ }^{6}$.

O problema da racionalidade jurídica que se propõe, por vezes, emancipatória, quando visualizada para o continente latino-americano (historicamente dominado e oprimido por processos de colonização interno e externo), conduz a equívocos que geram a reprodução de novas esferas hegemônicas, operadas pela despolitização política que não enfrenta a realidade concreta das vítimas. Ao copiar essa perspectiva nitidamente europeia, acaba por olvidar que o continente europeu, ao falar de emancipação, assume uma conotação por conta de quem está emancipando (sujeito dominador), ao ponto que, no espaço escravizado, explorado como mão de obra e, ao longo da história, colonizado

\footnotetext{
Sobre o pluralismo jurídico na América Originária, ver Machado (2015).
} 
pela matriz econômica no capitalismo, na matriz cultural como eurocentrismo e na matriz institucional como colonialismo, o termo deve ser substituído pelo conteúdo e pela perspectiva da libertação isso implica um efeito de transformação, e não meramente de reforma.

Portanto, o pluralismo jurídico, quando verificado criticamente para a América Latina, deve observar entre uma série de elementos próprios da geopolítica e da (geo)epistêmica regional a inadequação de uma racionalidade emancipatória, e voltar-se ao pensamento que, na relação dialética, possa lograr um salto ou passagem estratégica para o momento analético que redescobre a riqueza e a complexidade do outro em seu espaço de outridade.

Desse modo, esses sujeitos podem, na exigência política crítica dos mecanismos de produção e reprodução da vida (fonte material do direito), ir estruturando processos de libertação por meio da conscientização da opressão e da dominação como formas de conservação da alienação. Ora, a emancipação jurídica na América Latina logra eficazmente incluir o outro tardiamente em alguma armadilha dentro das três matrizes (institucional: colonialidade, cultural: monocultural e econômica: mercadocêntrica) e, no âmbito jurídico, uma perspectiva pluralista deve estar apta a desarmá-las.

Esses subsídios aludidos encontram certa aderência na proposta de emancipação do direito proporcionada pela leitura de Boaventura de Sousa Santos. Para essa tarefa, cumpre refletir sobre a pergunta que ele propõe: "Poderá o Direito ser emancipatório?"; imediatamente ressalta a resposta: "[...] um sim bastante relativado" (Santos, 2015, p. 4).

No entanto, o que importa na análise é as justificativas que permeiam a argumentação, porquanto, no tocante ao direito como regulação e como despolitização da sua capacidade de transformação, as lutas pela emancipação passaram a ser apenas pela inclusão no contrato social (Santos, 2015, p. 5). Para Santos (2015), a tarefa científica e política que se apresenta: "[...] como reinventar o Direito para lá do modelo liberal e demo-socialista e sem cair na agenda conservadora - e, mais ainda, como fazê-lo de modo a combater esta última de uma maneira mais eficaz" (p. 8).

Essa situação problemática está assentada em um consenso perverso que se manifesta no processo de globalização hegemônica, aquele traduzido na faceta do neoliberalismo como projeto neoconservador (Santos, 2015, p. 7), no qual o direito, diminuído à esfera da regulação violenta e opressiva, limita-se apenas a legitimar tais eventos.

Dessa forma, não abandonando a crença em uma possível capacidade emancipadora do direito, Boaventura de Sousa Santos (2015) refere: "[a] questão do papel do Direito na busca da emancipação social é, actualmente, uma questão contra-hegemónica que deve preocupar todos quantos, um pouco por todo o sistema-mundo, lutam contra a globalização hegemónica neoliberal" (p. 11). Assim, eis 
o local que habita o potencial emancipatório (Santos, 2015, p. 12) do direito: nas lutas globais que promovem os coletivos na contra-hegemonia global.

Para o sociólogo do direito de Coimbra, a crise da modernidade é representada na crise do contrato social, em que o predomínio dos processos de exclusão social assume maior relevo que os de inclusão; a ideia de inclusão aqui estabelecida corresponde ao chamado em admitir os valores da modernidade, mesmo assim não é um acesso irrestrito; ao contrário, apenas alguns contingentes logram conquistar essa dimensão, observando uma ou outra exceção que confirma a regra da exclusão. Para Santos, essa faceta assume duas formas: a primeira corresponde a situação do "pré-contratualismo", momento de obstacularização ao ingresso dos grupos que guardavam prévias expectativas de fazer parte do rol seleto; já a segunda ao "pós-contratualismo", aqueles que obtiveram o privilégio da inclusão são sumariamente excluídos e ainda veem dificultada qualquer pretensão de retornar a essa esfera (Santos, 2015, p. 18). Essa situação confirma a conjuntura crítica, o que leva à ideia de crise do contrato social assumir uma postura jurídica de garantia (momento que acima Sánchez Rubio destacava como impossibilidade de abandono).

A crise do contrato social moderno reside na inversão da discrepância entre a experiência social e a expectativa social. Após um longo período de expectativas positivas quanto ao futuro, pelo menos nos países centrais e semiperiféricos, entrámos num período de expectativas negativas para amplos sectores das populações de todo o planeta. [...] Com efeito, num período em que as expectativas sociais são negativas quando comparadas com as experiências sociais do quotidiano, a legalidade cosmopolita pode achar-se na situação de ser mais eficaz ao defender o status quo jurídico, isto é, a aplicação efectiva das leis tal como elas vêm nos livros. (Santos, 2015, p. 40)

Desse modo, na probabilidade de uma emancipação, aparecem duas alternativas que podem, ao menos, questionar criticamente as mazelas apresentadas como fascismo social ${ }^{7}$ e, na melhor das hipóteses, acaba possibilitando a abertura de novas expectativas ao momento de pouca credibilidade em saídas desse engodo produzido pela modernidade.

Assim, reclamando outro direito e também uma política diferenciada ante o

7 "Consideremos primeiramente os riscos. Em verdade, penso que estes podem ser resumidos a um só: a emergência do fascismo social. Não quero dizer com isso um regresso ao fascismo das décadas de 1930 e 1940. Ao contrário daquele que o precedeu, o fascismo de hoje não é um regime político, mas antes um regime social e civilizacional. Em vez de sacrificar a democracia às exigências do capitalismo, ele trivializa a democracia a ponto de se tornar desnecessário, ou sequer vantajoso, sacrificá-la para promover o capitalismo. É um tipo de fascismo pluralista, produzido pela sociedade, e não pelo Estado. Este se comporta, aqui, como mera testemunha complacente, se não mesmo como culpado ativo. Estamos a entrar em um período em que os Estados democráticos coexistem com sociedades fascizantes. Trata-se, por conseguinte, de uma forma inaudita de fascismo". (Santos, 2015, p. 21). 
contexto da globalização, de um lado, surge a proposta a) "contra-hegemônica" e, de outro, a de b) "cosmopolitismo subalterno" (Santos, 2015, p. 27). A luta contra-hegemônica, no entendimento de Santos, não significa somente combater as facetas nefastas, mas também enfrentar o âmago do processo e ousar apresentar alternativas. Logo, a ideia não é meramente de oposição, mas oposição propositiva de outros rumos que possam rechaçar o conformismo diante dos efeitos devastadores do capitalismo; assim, a contra-hegemonia se situa em movimentos organizados que compartilham um juízo sobre a exclusão como forma de negação da dimensão humana digna (Santos, 2015, p. 27). Por essa razão que o caráter opositivo dessa proposta alternativa se fundamenta em uma concepção explicitada assim: "[...] por uma justiça transformadora, quer dizer, por um projecto de justiça social que vá além do horizonte do capitalismo global. É nisto que reside o carácter opositivo e contra-hegemónico da legalidade cosmopolita" (Santos, 2015, p. 21).

Esse artifício se soma ao componente do cosmopolitismo subalterno, pois a globalização contra-hegemônica incorpora as diversidades de experiências e, em tal pluralidade, se assentam processos de comunicação e intercâmbios, cooperação e reciprocidade em apoio às lutas no mesmo sentido. Não obstante, a interconexão global produzida pelos meios tecnológicos de comunicação que colocam em colaboração diversos movimentos sociais e grupos alternativos em solidariedade pelas causas mais di- versas, as quais enfrentam os efeitos do fascismo social de forma criativa, isso se denomina cosmopolitismo subalterno ou cosmopolitismo dos oprimidos (Santos, 2015, p. 28). Essas categorias podem ser sintetizadas da seguinte maneira:

O cosmopolitismo subalterno é, portanto, uma variedade opositiva. Do mesmo modo que a globalização neoliberal não reconhece qualquer forma alternativa de globalização, assim também o cosmopolitismo sem adjectivos nega o seu próprio particularismo. O cosmopolitismo subalterno de oposição é a forma político-cultural de globalização contra-hegemónica. É, numa palavra, o nome dos projectos emancipatórios cujas reivindicações e critérios de inclusão social se projectam para além dos horizontes do capitalismo global. (Santos, 2015, p. 29)

Diante disso, afirmado esse contexto problemático e estabelecidas as propostas alternativas que intentam oferecer respostas concretas, Santos procura esclarecer quais seriam os espaços em que o direito poderia operar de forma reinventada, não apenas a serviço do processo hegemônico, mas também em uma mirada subalterna.

Consequentemente, esse lugar se encontra em três tipologias: a) práticas e perspectivas jurídicas que compuseram ou não a concepção ocidental do direito, e ambos os casos foram encobertos pelas concepções liberais (precursoras de uma ideia hegemônica — o monismo jurídico); 
b) formações jurídicas que se desenvolveram alheias ao Ocidente, em destaque as colônias e os Estados pós-coloniais, e, por último, c) as experiências propositivas de contra-hegemonia com base nas organizações e nos movimentos sociais (Santos, 2015, p. 12). O lugar das experiências de legalidade cosmopolita redunda em um processo que conduz os sujeitos negados por variadas dimensões em ocupar a esfera pública na condição subalterna e não submissa: "[...] a partir da sociedade civil incivil para onde foram atirados pelas estruturas do poder dominante" (Santos, 2015, p. 49). Para Santos (2015):

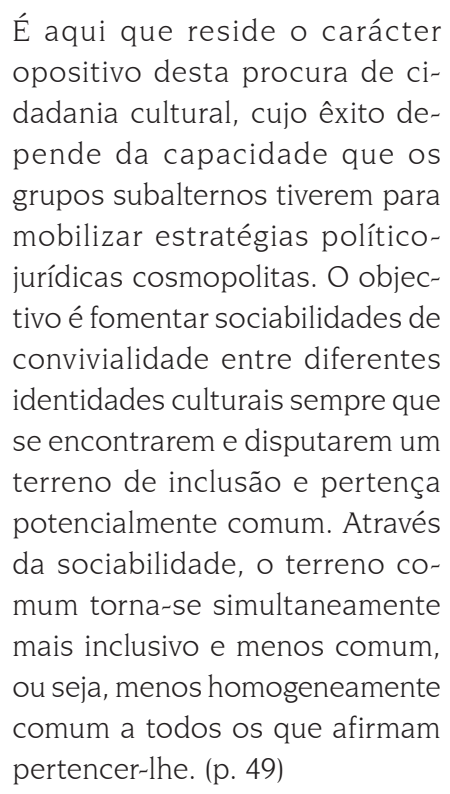

Percebe-se que a tarefa emancipadora do direito, na recuperação do seu caráter emancipador, está vinculada com o âmbito da afirmação do contrato social na perspectiva de garantir acesso aos meios de desenvolvimento dentro da faceta sociopolítica hegemônica; apesar de contra-hegemônica, a proposta jurídica emancipatória de Boaventura Santos se apresenta como esfera dimensionada na produção de inclusão social; seria esta a "capacidade emancipatória" que afirmou positiva e de maneira relativa anteriormente?

Ainda, os objetivos da legalidade cosmopolita se apresentam na recuperação da capacidade política do direito em enfrentar as mazelas do modelo global de dominação em forma de solidariedade entre os diversos setores subalternos (Santos, 2015, p. 46). A capacidade emancipatória do direito, na referida obra do autor, encontra seu limiar na perspectiva em oferecer alternativas no sistema global dominante, permitindo diminuir o índice de exclusão social pelo viés da inclusão no próprio sistema excludente e que, independentemente de ser o projetor da crise, é também o administrador que mais lucra, na medida em que o capitalismo em si não sofre com as crises cíclicas; ao contrário, reinventa-se nessas situações.

Dessa maneira, o horizonte da racionalidade emancipatória é um campo aberto para reflexões e propostas alternativas, passível de críticas profundas e contundentes, mas que, de fato, não deve ser rechaçado em sua totalidade, e sim potencializado nas perspectivas que ativam as capacidades sociopolíticas insurgentes dos atores históricos e suas necessidades.

Assumindo essa postura, não parecem obrigatórias as leituras teóricas europeias ou norte-americanas para que o pluralismo jurídico seja emancipatório, 
ou mesmo para elaborar críticas, basta, à maneira da Filosofia da Libertação (Dussel, 2011) latino-americana, ousar pensar por intermédio das facetas perversas que atingem a zona periférica e a confirmam como periférica (um pensamento situado), ou mesmo, por essa condição, afirmar que o estado de periferia já é propriamente um elemento constituído pela conjuntura sistêmica dominante. Acontece que, nessa zona, local em que foi produzida a faceta encobridora da modernidade, também podem emergir alternativas críticas provocadoras que desestabilizam o sistema moderno e não somente colocam em crise seus paradigmas, como também superam criativamente o centro global do poder.

\subsection{Por uma potencialidade libertadora do pluralismo jurídico}

Dessa maneira, partindo da crítica de Enrique Dussel às concepções emancipatórias da modernidade e da pós-modernidade, compreendidas como impossibilidade para a realidade periférica (Dussel, 2005, p. 74) continental, afinal a: "América Latina, en cambio, nació al mismo tiempo que la Modernidad, pero su 'otra cara' necesaria, silenciada, explotada, dominada" (Dussel, 2005, p. 75); por esse ângulo, põe em crise a proposta da racionalidade emancipatória moderna vinculada ao pensamento da comunidade de comunicação ou mesmo da sociedade cosmopolita de Boaventura Santos (com seu viés inclusivo).
Para E. Dussel (2005), a proposta deve ser originada não meramente a partir de uma singularidade, de um "si mesmo" ou "nós coletivo", e sim da seguinte forma:

Lo esencial, entonces, para una filosofía de la liberación, no es el "yo" o el "nosotros" (aun como "comunidad de comunicación") o la "sociedad abierta", que de hecho puede "cerrarse" en una totalización totalitaria de la Totalidad, en su "lo público (Öffentlichkeit)" burocratizado, sino el "tú", el "vosotros", "el otro" de toda comunidad de comunicación la exterioridad transcendental a toda comunidad y ontología; trans-ontológica, entonces, que con Lévinas hemos denominado la alteridad metaísica del Otro (para diferenciarla de la metafísica vulgar o dogmática, óntica). (p. 97, grifo nosso)

A denúncia que faz E. Dussel no presente texto trata-se do fato que esse sujeito, em sua "outridade", não fez parte da comunidade de comunicação emancipatória senão apenas como parte receptiva do acordo. Logo, como poderia ser integrado? Sob a fórmula da igualdade e seu binômio "diferença"! Caso seja essa a resposta, algumas observações abaixo devem ser esclarecidas.

O relevante da proposta reflexiva é a indagação a respeito de se esse mesmo sujeito não pode construir suas próprias possibilidades e ignorar o consenso global e hegemônico, bem como as alternativas advindas do centro que irradia possibilidades, princípios e racionalida- 
des; a questão do Outro não se apresenta meramente como transcendentalidade ao Nós: "[...] sino transcendental a la misma comunidad. Sin embargo, de hecho, en la comunidad de comunicación 'real', 'el Otro' es ignorado, desconocido - no reconocido - como momento ético de una estructura vigente de injusticia" (Dussel, 2005, p. 101).

Nesse sentido, a questão explícita da exclusão do outro se traduz não somente como afetada pelos efeitos do sistema, mas também pelos efeitos da impossibilidade de participar efetivamente da comunidade de comunicação "real", ou seja, participar como membro e não mero expectador passivo. Essa condição se dá por conta da historicidade silenciada: "[...] para América Latina, cultura periférica no es un tema solamente teórico, es ante todo una experiencia fática, ético-práctica, que cumplió ya medio milenio en 1992" (Dussel, 2005, p. 101).

Assim, só a afirmação da exterioridade do outro pode irromper na totalidade; entenda-se "totalidade" como sistema fetichizado da própria modernidade, enclausurada em suas próprias promessas de futuro infalível ${ }^{8}$, e que não se abre para além das possibilidades que, pelo seu âmago, pode oferecer como alternativas. Acontece que, na intempérie do projeto totalizador, encontram-se as possibilidades aventadas e elaboradas na condi-

8 Sobre o assunto, verificar o artigo intitulado "Pluralismo jurídico e justiça comunitária na América Latina: potencialidades a partir da sociologia das ausências e das emergências (Leal e Machado, 2013). ção de outras expectativas. Não se está pensando em probabilidades renovadas, mas probabilidades de outro projeto, um projeto de libertação que está além da emancipação (Dussel, 2005, p. 104). A insuficiência de somente denunciar a exterioridade da América Latina e a originalidade encoberta dos seus povos e culturas se encontra na abertura da possibilidade de mera inclusão no processo racional moderno, e a questão se trata de:

\begin{abstract}
Os excluídos não devem ser incluídos (seria como introduzir o Outro no mesmo) no antigo sistema, mas devem participar como iguais em um novo momento institucional (a nova ordem política). Não se luta pela inclusão, mas sim pela transformação - contra Iris Young, J. Habermas e tantos outros que falam de "inclusão". (Dussel, 2007, p. 110)
\end{abstract}

A interpelação ética do oprimido supera a exigibilidade política do direito emancipatório, pois a exigência das necessidades fundamentais para seguir vivendo, como no caso da fome, já configura um pedido de justiça que denuncia algum tipo de injustiça perpetrado (Dussel, 2007, p. 119). Na maioria das vezes, essa injustiça é um elemento histórico e que se manifesta hegemonicamente nas zonas periféricas em torno dos centros de poder ou como efeito do exercício hegemônico deste último. Afinal, que tipo de comunidade pode ser pensada pelos arquétipos centrais, que ignoram a dor dos povos oprimidos? Seria perpetrar o mito tutelar de um Ginés de Sepúlveda ao creditar apenas ao locus da solidariedade liberal em detrimento de 
potencializar a crítica desestabilizadora do sistema pelo próprio ser dolorido, pois obviamente não se trata de pensar pela dor do outro, mas de se comunicar com este para ouvir a sua interpelação como provocação ética à racionalidade (irracional) do sistema imperante 9 .

Diante dessa afirmação, E. Dussel passa a diferenciar a ideia de emancipação dos processos de libertação e principalmente da práxis de libertação.

Esto nos permite concluir que la "intención emancipadora" o el acto de "emancipación" no puede identificarse con la "intención liberadora" o la praxis de "liberación". [...] "Emancipar" es transformar a la "comunidad de comunicación real" a la luz de la "comunidad de comunicación ideal"; emancipar es "la realización, en la comunidad real de comunicación, de una libertad sin dominación propia de la comunidad ideal de comunicación". Es decir, a diferencia del interés estratégico (de la racionalidad instrumental) o del interés práctico o comunicativo, el interés emancipatorio se dirige a la superación de las alienaciones - pero no creo deformar su contenido si agrego, reductivamente, alienaciones de la ciencia, del conocimiento, de la argumentación; es decir en el nivel cognitivo final. Mientras que la "praxis liberadora", subsumiendo la intención emancipadora y el acto racional emancipador, no olvida

9 "La exigencia ética 'Liberta al Otro, al pobre!" es la condición de posibilidad del nuevo argumentar real; es permitir al Otro-pobre 'ser parte' del nuevo nosotros argumentativo, que está dispuesto a llegar a un nuevo acuerdo [...]" (Dussel, 2011, p. 121). (sino que da articulado relieve a las exigencias éticas surgidas en la lucha contra la miseria) a la comunidad político-económica de vida, como proyecto (y es lo que se denomina "proyecto de liberación" constituido desde una "intención" liberadora). Dicha praxis liberadora considera siempre en su descripción la problemática de las estructuras y de la praxis de dominación - en el nivel de la corporalidad, la producción, la economía, como antropología y ética - que el discurso crítico de Marx analizó de manera abstracta (pero concreta con respecto a Lévinas o Apel) y esencial (que guardan hoy total pertinencia, si se tiene en cuenta su nivel de abstracción y esencialidad). (Dussel, 2011, p. 121, grifo nosso)

Por fim, essa perspectiva de superação da racionalidade emancipadora pelo projeto de libertação pressupõe, no âmbito do estudo, um consenso crítico $^{10}$, recordando

10 Esse consenso crítico do povo não pôde ser descoberto nem pela primeira Escola de Frankfurt, nem por K. O. Apel ou J. Habermas. Por isso, não puderam articular a "teoria crítica" com os atores políticos históricos (que já não tiveram ao desaparecer pelo Holocausto a comunidade judia, e por integrar a classe operária ao "milagre alemão"). Nós, por outro lado, devemos nos articular a esse ator coletivo, bloco que nasce e pode desaparecer segundo conjunturas, chamado povo, ou novos movimentos sociais de grande vitalidade, que constroem "o poder de baixo". O povo toma, então, "consciência para-si". Reconstrói a memória de suas lutas, feitos esquecidos e ocultos na história dos vencedores - como assinala Walter Benjamim-. Ainda não é a "consciência da classe operária", mas não se opõe a ela; integra-a. É a consciência da classe camponesa, dos povos indígenas, das feministas, dos antirracistas, dos marginais... de todos esses fantasmas que vagam na exterioridade do sistema. Consciência de ser povo. (Dussel, 2007, p. 100). 
que: "[ol consenso crítico dos dominados é o momento do nascimento de um exercício crítico da democracia" (Dussel, 2007, p. 109); logo, libertar significa:

[c]onstruir una "comunidad de comunicación y de vida históricoposible" más justa, más racional (como realización del "proyecto utópico-concreto" de liberación). "Liberar" parte de una "comunidad de vida real" gracias a una praxis reformista o revolucionaria (ninguna de las dos puede ser descartada a priori), y desde la "interpelación del Otro", es decir, como exigencia ética de la "comunidad de comunicación y de vida ideal". (Dussel, 2005, p. 124).

Em síntese, ficou expresso no desenvolvimento desta discussão uma abertura de perspectiva teórica e crítica que privilegiou avaliar o pluralismo jurídico não mais por transplantes da centralidade do Norte global, mas agora de forma incisiva e comprometida com a produção de conhecimento gerada pela Filosofia da Libertação latino-americana (originária e proveniente do Sul global) e mediada por ela.

\section{CONSIDERACÕES}

A temática do PJCP tem a potencialidade de apresentar uma concepção material do direito (embasando-se nas necessidades humanas fundamentais), verificá-la e fortalecê-la conciliando as experiências normativas das comunidades com a lógica participativa (democrática), fazendo uma junção entre a esfera do direito com a da política. Ainda, cabe referir que essa proposta não se limita apenas a esses elementos, pois é possível constatar que comporta uma abordagem pedagógica, ética e também uma expansão da dimensão política do espaço público (reinventado), que prioriza um sujeito histórico concreto com capacidade de produzir uma forma jurídica.

Ademais, essa tipologia de pluralismo jurídico também apresenta uma racionalidade que guarda uma capacidade emancipatória, elemento que, problematizado acima, revelou suas limitações quando analisado dentro da realidade histórica concreta dos sujeitos na América Latina. Tais limitações representam a abertura para a reflexão crítica, evidenciando as possibilidades e condições reais de libertação daquilo que foi pensado por meio de uma prática histórico-concreta e um pensamento situado, capaz de subsidiar elementos para assentar outro viés de racionalidade, renovando as fontes da pluralidade normativa.

Portanto, se a proposta inicial era explorar criticamente a capacidade da racionalidade emancipatória do direito no fenômeno do pluralismo jurídico, em especial aquele visualizado desde o cenário latino-americano, é possível concluir que os limites foram expostos, refletidos e questionados por meio de uma renovada mirada liberadora, como horizonte racionalizado que se propõe ir além dos limites da modernidade e de sua condição periférica; uma racionalidade propositiva, protagonista e que emerge desde a condição do outro, que não é marginal no sistema, mas 
excluído da comunidade deste. Ao final, entende-se que a racionalidade emancipatória deve ser subsumida na abertura crítica ao sistema de direito e, posteriormente, potencializada pelo pensamento da realidade situada como movimento de transformação do sistema de direito e suas matrizes de colonialidade, eurocentricidade e mercadocêntrica.

\section{REFERÊNCIAS BIBLIOGRÁFICAS}

Dussel, E. (2005). Ética del discurso y ética de la liberación: debate 1989-1997. Madri: Editorial Trotta.

Dussel, E. (2007). 20 Teses de Política. $1^{a}$ ed. Buenos Aires: Consejo Latinoamericano de Ciencias Sociales - Clacso; São Paulo: Expressão Popular.

Dussel, E. (2011). Filosofía de la liberación. México: FCE.

Echeverría, Bolívar. (2012). Modernidad y blanquitud. México: Ediciones Era.

Leal, J. da S. e Machado, L. (2013). Pluralismo jurídico e justiça comunitária na América Latina: potencialidades a partir da Sociologia das ausências e das emergências. Crítica Jurídica. Revista Latinoamericana de Política, Filosofía y Derecho, 1 (35): 165-195.

Machado, L. (2015). Juridicidades insurgentes: elementos para o pluralismo jurídi- co de libertação latino-americano (Tese de Doutorado em Direito). Programa de Pós-graduação em Direito, Universidade Federal de Santa Catarina, Florianópolis, Santa Catarina, Brasil). Recuperado de https://repositorio.ufsc.br/xmlui/bitstream/handle/123456789/157392/336538. pdf? sequence $=1$ EisAllowed $=\mathrm{y}$

Sánchez-Rubio, D. (2010). Pluralismo jurídico e emancipação social. Em Wolkmer, A. C. L., Morcilo, I. F. (orgs.), Pluralismo jurídico: os novos caminhos da contemporaneidade (Cap. 3, pp. 51-66). São Paulo: Saraiva.

Santos, B. de S. (2003). Poderá o direito ser emancipatório? Revista Crítica de Ciências Sociais, 1(65): 3-76.

Santos, B. de S. (2010). Refundación del Estado en América Latina. Perspectivas desde una epistemología del Sur. Lima: Instituto Internacional de Derecho y Sociedad.

Wolkmer, A. C. (1994; 2001). Pluralismo jurídico: fundamentos de uma nova cultura do direito. São Paulo: Alfa-Ômega.

Wolkmer, A. C. (2010). Pluralismo jurídico: um espaço de resistência na construção de direitos humanos. Em Wolkmer, A. C. e Lixa, I. M. F. (orgs.), Pluralismo jurídico: os novos caminhos da contemporaneidade (Cap. 2, pp. 37-50). São Paulo: Saraiva.

Wolkmer, A. C. (2012). Introdução ao pensamento jurídico crítico. $8^{a}$ ed. São Paulo: Saraiva. 
